\section{Attitudes about COVID-19 Lockdown among General Population, France, March 2020}

\author{
Patrick Peretti-Watel, Valérie Seror, \\ Sébastien Cortaredona, Odile Launay, Jocelyn Raude, \\ Pierre Verger, François Beck, Stéphane Legleye, \\ Olivier L'Haridon, Jeremy Ward, for the Coronavirus \\ and Confinement: Enquête Longitudinale \\ (COCONEL) Study Group
}

\begin{abstract}
Author affiliations: VITROME (Vecteurs-Infections Tropicales et Méditerranéennes), Institut Méditerranée Infection, Aix Marseille Université, Marseille, France (P. Peretti-Watel, V. Seror,

S. Cortaredona, J. Ward); Observatoire Régional de la Santé Provence-Alpes-Côte d'Azur, Marseille (P. Peretti-Watel,

P. Verger); Centre d'Investigation Clinique Cochin-Pasteur, Paris, France (O. Launay); École des Hautes Études en Santé Publique, Rennes (J. Raude); Centre de Recherche en Épidémiologie et Santé des Populations, Villejuif, France (F. Beck, S. Legleye); Université de Rennes, Rennes (O. L'Haridon); Groupe d'Étude des Méthodes de l'Analyse Sociologique de la Sorbonne, Paris (J. Ward)
\end{abstract}

DOI: https://doi.org/10.3201/eid2701.201377

Because the effectiveness of a coronavirus disease lockdown in curbing coronavirus disease spread depends on public support, acquiring real-time information about the way populations reacted to the lockdown is crucial. In France, such public support remained fragile among low-income persons, probably because the lockdown exacerbated preexisting social inequalities and conflicts.

$\mathrm{D}$ uring the spring of 2020, because of the coronavirus disease (COVID-19) pandemic, $>3$ billion persons worldwide lived under lockdown, and many of them were probably angry, uncertain, and distrustful of their national leaders (1). Thus, acquiring realtime information about the way populations react and comply to such stringent measures across different socio-economic groups and sociocultural contexts is crucial (2). Social acceptability is especially important in the case of France, because the general population did not adhere to governmental recommendations against the previous 2009 influenza A(H1N1) pandemic, during which only $8 \%$ of adults complied with the mass vaccination campaign promoted by health authorities $(3,4)$.

To investigate attitudes toward the lockdown among the general population in France, we conducted a cross-sectional online survey among a nationally representative sample $(\mathrm{N}=1,012)$ of residents $\geq 18$ years of age (Table). The survey was administered during March 27-29, about 10 days after the nationwide lockdown was introduced. To limit selection bias, categories of persons who are less prone to participate in internet surveys (e.g., workers and older persons) were oversampled, and the invitational email did not mention the theme of the survey. In terms of response bias, self-administered questionnaires tend to yield fewer reports in the socially desirable direction than do interviewer-administered questionnaires, and online surveys might have the lowest levels of social-desirability bias (5). We computed participants' equivalized household income per month, taking into account household size and composition. Low income refers to the bottom quartile, medium income to the second and third quartiles, and high income to the top quartile. Participants were asked to express their level of agreement toward 12 statements related to lockdown. We asked them whether they were experiencing financial difficulties because of the lockdown. We also asked for household size and housing surface area to identify participants confined in an overcrowded household.

Most participants supported the current lockdown as the only effective way to fight the epidemic and the need to maintain it for several more weeks; however, this support was significantly lower ( $\mathrm{p}<0.001$ by $\chi^{2}$ test) among low-income respondents (Table). Strong support was observed across all income groups in favor of strengthening controls to making the lockdown more effective. Only a few respondents (more frequently low-income respondents) expressed open criticisms, including statements indicating that the lockdown is "disproportionate considering the real gravity of the epidemic" (35\% among low-income respondents vs. $10 \%$ among high-income respondents) and that it should be less coercive to be more acceptable (33\% among low-income respondents vs. $13 \%$ among high-income respondents).

However, the consensus for the lockdown was based on the fact that it appeared a stopgap measure implemented because of a lack of alternatives: $66 \%$ of respondents agreed that the lockdown was the consequence of the lack of hospital resources, $65 \%$ agreed that mass testing could replace the lockdown, and $50 \%$ considered that the lockdown could have been "avoided by the widespread wearing of masks." Once again, such statements were more frequent among low-income respondents. Similarly, 
Table. Opinion about the coronavirus disease lockdown among 1,012 respondents to the Coronavirus and Confinement: Enquête Longitudinale (COCONEL) survey, France, March 27-29, 2020*

\begin{tabular}{|c|c|c|c|c|c|}
\hline \multirow[b]{2}{*}{ Statement or condition } & \multicolumn{4}{|c|}{$\begin{array}{c}\% \text { Respondents who agreed with statement, by } \\
\text { income level }(+\mathrm{MoE})\end{array}$} & \multirow[b]{2}{*}{$p$ value } \\
\hline & Overall & $\begin{array}{c}\text { Lower } \\
\text { income, } \mathrm{n}= \\
216\end{array}$ & $\begin{array}{c}\text { Medium } \\
\text { income, } \mathrm{n}= \\
566\end{array}$ & $\begin{array}{c}\text { Higher } \\
\text { income, } n= \\
230\end{array}$ & \\
\hline \multicolumn{6}{|l|}{ The lockdown: } \\
\hline Is the only effective way to fight & $88( \pm 2)$ & $81( \pm 5)$ & $90( \pm 2)$ & $93( \pm 3)$ & $<0.001$ \\
\hline Should last several more weeks to be effective & $93( \pm 1)$ & $89( \pm 4)$ & $94( \pm 2)$ & $98( \pm 2)$ & $<0.01$ \\
\hline Should be strengthened to be effective & $80( \pm 2)$ & $75( \pm 6)$ & $82( \pm 3)$ & $81( \pm 5)$ & NS \\
\hline Is disproportionate considering the real gravity of the epidemic & $20( \pm 2)$ & $35( \pm 6)$ & $18( \pm 3)$ & $10( \pm 4)$ & $<0.001$ \\
\hline Should be less coercive to be more acceptable & $22( \pm 3)$ & $33( \pm 6)$ & $21( \pm 3)$ & $13( \pm 4)$ & $<0.001$ \\
\hline Is the consequence of the lack of hospital resources & $66( \pm 3)$ & $72( \pm 6)$ & $68( \pm 4)$ & $54( \pm 6)$ & $<0.001$ \\
\hline Could have been avoided by the widespread wearing of masks & $50( \pm 3)$ & $61( \pm 7)$ & $51( \pm 4)$ & $40( \pm 6)$ & $<0.001$ \\
\hline Could be replaced by mass screening tests & $65( \pm 3)$ & $74( \pm 6)$ & $65( \pm 4)$ & $60( \pm 6)$ & $<0.01$ \\
\hline Has already disastrous economic consequences & $93(+2)$ & $93( \pm 3)$ & $91(+2)$ & $96(+2)$ & NS \\
\hline Will cause family tragedies & $76(+3)$ & $78( \pm 6)$ & $76( \pm 4)$ & $75( \pm 6)$ & NS \\
\hline Causes too much restriction on civil liberties & $41(+3)$ & $58( \pm 7)$ & $40( \pm 4)$ & $28( \pm 6)$ & $<0.001$ \\
\hline Is an opportunity to develop local solidarity & $91(+2)$ & $92(+4)$ & $90(+2)$ & $91(+4)$ & NS \\
\hline Experiencing financial difficulties because of the lockdown & $19(+2)$ & $40( \pm 7)$ & $16( \pm 3)$ & $6( \pm 3)$ & $<0.001$ \\
\hline Confined in an overcrowded household $\dagger$ & $9( \pm 2)$ & $23( \pm 6)$ & $7( \pm 2)$ & $1( \pm 1)$ & $<0.001$ \\
\hline \multicolumn{6}{|c|}{$\begin{array}{l}\text { *Sample was randomly drawn from online research panel of }>750,000 \text { nationally representative households of the general population in France, } \\
\text { developed and maintained by the Institut Français d'Opinion Publique, a survey research firm (https://www.ifop.com). Collected data were weighted to } \\
\text { match official national census statistics for sex, age, occupation, size of population in the area of residence, and region. The study design was approved } \\
\text { by the Ethics Committee of the University Hospital Institute Méditerranée Infection (approval no. 2020-018). MoE, margin of error at } 95 \% \text { confidence level; } \\
\text { NS, not statistically significant. } \\
\text { †Defined as }<194 \text { square feet per capita. }\end{array}$} \\
\hline
\end{tabular}

although all socioeconomic groups acknowledged some major drawbacks (including disastrous economic consequences and family tragedies), lowincome respondents were more likely than highincome respondents to state that the lockdown was causing "too much restriction on civil liberties" (58\% vs. $28 \%$ ).

Social differences in attitudes toward the lockdown are probably related to practical differences in persons' living conditions during the lockdown. After 10 days of confinement, $40 \%$ of respondents in the low-income group were already reporting financial difficulties because of the lockdown (compared with $6 \%$ among high-income respondents). In terms of housing conditions, $9 \%$ of participants were confined in an overcrowded household, but that was the case for $23 \%$ of low-income respondents (compared with $1 \%$ of high-income respondents). Overcrowded housing can impair mental health, and the lockdown made crowded situations even more unbearable because engaging in outdoor activities typically is the easiest way to cope with such situations $(6,7)$.

In France, as in most other countries, the COVID-19 pandemic fueled contradictory information and intense controversies in traditional and social media. Our survey suggests that a social consensus has been maintained in France in favor of the national lockdown and that excessive politicization of public health has been avoided so far (8). However, this consensus remained fragile. First, opinion might have changed if the public got the impression that authorities did not promote alternatives fast enough to end the confinement period. Second, as exemplified by the lower support observed in the poorest groups, the pandemic and the lockdown both exacerbated existing social inequalities and conflicts; besides social inequalities in terms of income and housing conditions, hospital workers in France had been on strike for months during the previous year demanding more resources, and many opponents accused the government of impinging on civil liberties during the so-called "yellow vests" protest movement.

In summary, in late March, most persons in France did support the lockdown; however, such consensus remained fragile because of existing social inequalities and conflicts. Continuous monitoring of population's attitudes and practices during the pandemic will remain key for guiding the public health response (9) and communication strategy (10).

The COCONEL survey was funded by France's National Agency for Research (grant no. ANR-20-COVI-0035-01), la Fondation de France, and France's National Research Institute for Sustainable Development.

\section{About the Author}

Dr. Peretti-Watel is research director at the French National Institute for Medical Research. His primary research interests include perceptions, attitudes, and behaviors toward infectious diseases. 


\section{References}

1. The Lancet. COVID-19: learning from experience [editorial]. Lancet. 2020;395:1011. https:/ / doi.org/10.1016/ S0140-6736(20)30686-3

2. Betsch $\mathrm{C}$. How behavioural science data helps mitigate the COVID-19 crisis. Nat Hum Behav. 2020;4:438. https:/ / doi.org/10.1038/s41562-020-0866-1

3. Schwarzinger M, Flicoteaux R, Cortarenoda S, Obadia Y, Moatti JP. Low acceptability of A/H1N1 pandemic vaccination in French adult population: did public health policy fuel public dissonance? PLoS One. 2010;5:e10199. https:/ / doi.org/10.1371/journal.pone.0010199

4. Sherlaw W, Raude J. Why the French did not choose to panic: a dynamic analysis of the public response to the influenza pandemic. Sociol Health Illn. 2013;35:332-44. https://doi.org/10.1111/j.1467-9566.2012.01525.x

5. Kreuter F, Presser S, Tourangeau R. Social desirability bias in CATI, IVR, and web surveys. The effects of mode and question sensitivity. Public Opin Q. 2008;72:847-65. https://doi.org/10.1093/poq/nfn063

6. National Housing Federation. Housing issues during lockdown: health, space and overcrowding [cited 2020 Sep 1]. https://www.housing.org.uk/globalassets/files/ homes-at-the-heart/housing-issues-during-lockdownhealth-space-and-overcrowding.pdf

7. Peretti-Watel P, Alleaume C, Léger D, Beck F, Verger P; COCONEL Group. Anxiety, depression and sleep problems: a second wave of COVID-19. Gen Psych. 2020;33:e100299. https:/ / doi.org/10.1136/gpsych-2020-100299

8. Gostin LO. Language, science, and politics: the politicization of public health. JAMA. 2018;319:541-2. https://doi.org/ 10.1001/jama.2017.21763

9. Anderson RM, Heesterbeek H, Klinkenberg D, Hollingsworth TD. How will country-based mitigation measures influence the course of the COVID-19 epidemic? Lancet. 2020;395:931-4. https:/ / doi.org/10.1016/ S0140-6736(20)30567-5

10. Cowper A. Covid-19: are we getting the communications right? BMJ. 2020;368:m919. https://doi.org/10.1136/ bmj.m919

Address for correspondence: Patrick Peretti-Watel, VITROME, IHU Méditerranée Infection, 19-21 bd Jean Moulin, 13005 Marseille, France; email: patrick.peretti-watel@inserm.fr

\section{Risk for SARS-CoV-2 Infection in Healthcare Workers, Turin, Italy}

\author{
Andrea Calcagno, Valeria Ghisetti, Teresa Emanuele, \\ Mattia Trunfio, Silvia Faraoni, Lucio Boglione, \\ Elisa Burdino, Sabrina Audagnotto, Filippo Lipani, \\ Marco Nigra, Antonio D'Avolio, Stefano Bonora, \\ Giovanni Di Perri
}

Author affiliations: University of Torino, Torino, Italy (A. Calcagno, M. Trunfio, S. Audagnotto, F. Lipani, A. D’Avolio, S. Bonora, G. Di Perri); Azienda Sanitaria Locale Città di Torino, Torino (V. Ghisetti, T. Emanuele, S. Faraoni, E. Burdino, M. Nigra); University of Eastern Piedmont, Novara, Italy (L. Boglione)

DOI: https://doi.org/10.3201/eid2701.203027

We measured severe acute respiratory syndrome coronavirus 2 spike protein subunits S1/S2 antibodies by using capillary electrophoresis and a chemiluminescence immunoassay for 5,444 active healthcare workers in Italy. Seroprevalence was $6.9 \%$ and higher among participants having contact with patients. Seroconversion was not observed in $37 / 213$ previously infected participants.

$\mathrm{T}$ he ongoing coronavirus disease (COVID-19) pandemic is having an unprecedented impact on the worldwide population. Seroconversion for severe acute respiratory syndrome coronavirus 2 (SARSCoV-2) was described to occur 7-14 days after onset of symptoms, 100\% within 19 days after clinical onset (1). Recent serologic data suggest that, in affected areas, SARS-CoV-2 infection had been acquired by more persons than what could be extrapolated by PCR analysis of nasopharyngeal swab specimens (1-3).

Large studies reported seroprevalences of $1 \%-$ $6.9 \%$ (2). In February 2020, seroprevalence for 12 blood donors in Lodi, Italy, a heavily affected zone, was as high as $23 \%$ (3). Studying high-risk persons, such as healthcare workers, could be relevant for implementing preemptive and protective strategies. In Italy, 30,383 healthcare workers (of 253,619 confirmed cases; $12.0 \%$ ) have been reported to be infected since the beginning of the pandemic (4).

Active healthcare workers ( $\mathrm{n}=7,457$ ) from Azienda Sanitaria Locale Città di Torino public hospitals and outpatient services (Turin, Italy) were invited by email and printed leaflets to participate in our study. During April 17-May 20, 2020, they underwent blood withdrawal. SARS-CoV-2 antibodies were measured by using capillary electrophoresis and chemiluminescence immunoassay 